\title{
Sensory and chemical characteristics of 'dry' wines awarded gold medals in an international wine competition
}

\author{
Manuel Malfeito-Ferreira ${ }^{a}$, Charles Diako $^{b}$ and Carolyn F. Ross ${ }^{c}$ \\ aLinking Landscape, Environment, Agriculture and Food Research Center (LEAF), Instituto Superior de

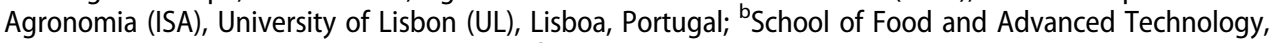 \\ Massey University, Auckland, New Zealand; 'School of Food Science, Washington State University, Pullman, \\ WA, USA
}

\begin{abstract}
The objective of this work was to identify the sensory attributes associated with the highest awards given to wines in large competitions. Data from the Mundus Vini annual wine competitions (editions) from 2014 to 2016 were used. The chemical analysis and sensory attributes were subjected to cluster analysis and logistic ridge regression to identify predictors of grand gold and gold medal awards. High ethanol levels and sugar concentrations, mainly in red wines, were observed. For both red and white wines, three clusters were identified which broadly separated grand gold from gold medal awarded wines. The discrimination of $G$ wines was mainly due to higher scores of bitterness and green/vegetative characters in both red and white wines, and with barnyard attributes only in red wines. The prediction regression for white wines showed that the exotic fruit was the most valued sensory attribute along with the quality indicators of body and complexity. Red wines had a higher number of predictors, including positive attributes like dried fruits and spicy or negative attributes like green/vegetative and red berries. This study identified the most relevant sensory features most valued by competition jurors, which were broadly consistent with the so-called international commercial wine style.
\end{abstract}

\section{ARTICLE HISTORY}

Received 29 March 2019

Accepted 31 July 2019

\section{KEYWORDS}

Wine challenge; sensory attributes; competition

\section{Introduction}

Wine challenges are conducted around the world as a means to promote wine sales (Peattie, 1995). Countries, regions or producers participate in these wine competitions with the goal of improving their competitiveness, reputation and esteem. As such, the obtained awards are regarded as efficient marketing vehicles. At the point of purchase, consumers often rely on the medals displayed on the bottles in making purchase decisions (Herbst \& Von Arnim, 2009).

Because of the importance of these wine challenges and to exert a level of quality control on such judging events, the International Vine and Wine Office (OIV) has published guidelines for the organization of these events which organizers must meet to 
have the events audited and certified (OIV, 2009). These guidelines include the tasting protocol, tasting sheets and score range of the different levels of award. For example, wines associated with at least 92 points are awarded Grand Gold. Gold medals are awarded to wines with a mean score of at least 85 points, while the thresholds for Silver and Bronze medals are 82 and 80 points, respectively. The number of wines awarded medals must not exceed $30 \%$ of the total of samples presented at the competition and if this percentage is exceeded, the samples that obtained the lowest score are eliminated (OIV, 1994).

As may be expected, the output of these competitions has been subject to controversy (Cliff \& King, 1997; Cliff \& King, 1999; Hodgson, 2008; Honoré-Chedozeau, Ballester, Chatelet, \& Lempereur, 2015; Scaman, Dou, Cliff, Yuksel, \& King, 2001). In a recent study, researchers speculated that red wines with residual sugar levels higher than $4 \mathrm{~g} / \mathrm{L}$ and ethanol higher than $14 \%(\mathrm{v} / \mathrm{v})$ tend to be favoured by the OIV tasting protocol in the Mundus Vini Challenge (Loureiro, Brasil, \& Malfeito-Ferreira, 2016). These authors hypothesized that average levels of $8 \mathrm{~g} / \mathrm{L}$ residual sugar and $15 \%(\mathrm{v} / \mathrm{v})$ ethanol of the Grand Gold awardees reported in the 2012 edition reflected the jury preference for Italian Amaronestyle wines. In addition, resolving ties between wines is performed by increasing the number of decimal places and so distinction among wines has dubious statistical validity (Bodington \& Malfeito-Ferreira, 2017).

The Mundus Vini Challenge is held twice annually in Dusseldorf, Germany (spring and summer of each year) and for each session, receives over 4000 submissions from wineries all over the world. The Mundus Vini Challenge publishes a list of the wines that are awarded medals, along with a basic wine chemical analysis (ethanol, titratable acidity and residual sugar) and tasting notes generated by the judges (www.mundusvini.com). Using these published data, the present study examined the relationship among wine features (chemical and tasting notes) and the likelihood of a given wine being awarded gold or grand gold medal. These results will be useful to wine professionals in order to better understand the influences involved in the awarding of a medal in this competition, with a further extension to other wine competitions.

\section{Materials and methods}

\subsection{Challenge description}

The description of the Mundus Vini Challenge description can be found at https:// www.meininger.de/en/mundus-vini/results. The jury of wine experts was composed of enologists, winemakers, professional wine traders, sommeliers and expert journalists that tasted the wines in a series of 'blind' tasting rounds. Wines were organized according to their product category (still wine, sparkling wine, fortified wine, slightly sparkling wine), country of origin, growing area, quality level and flavour profile, and evaluated in accordance with the international 100-point scheme of the International Organisation of Vine and Wine (OIV, 1994), which is also recognized by the Union Internationale des Oenologues (UIOE). The percentage of wines allocated to receive medals in the competition was limited to $40 \%$ of the submitted wines with the highest points reached in their relevant category. The award grades were Grand Gold, Gold and Silver. 


\subsection{Data}

Data from Mundus Vini Challenge were retrieved from the website www.mundusvini. com (accessed March to July 2016; Table 1). The data obtained included the winery, vintage year, chemical analysis (ethanol content, residual sugar, total acidity) and whether the wine was awarded a Grand Gold or Gold medal. Wines that were awarded Silver medals were not included in this analysis. For the 2014-2016 wines, a more detailed sensory profile of the wines awarded grand gold or gold medals was provided in addition to the OIV tasting attributes. This sensory profile included flavour descriptors and indicators of a general impression as evaluated by the wine expert panel (Table 2).

In the present study, we focused on the grand gold and gold white and red wines meeting the definition of 'dry' in the challenge editions from 2014 Spring, 2014 Summer, 2015 Spring, 2015 Summer to 2016 Spring. The definition given by OIV standards is that dry wines contain a maximum of $4 \mathrm{~g} / \mathrm{L}$ glucose plus fructose, medium dry wines contain between 4 and $12 \mathrm{~g} / \mathrm{L}$, semi-sweet contain between 12 and $45 \mathrm{~g} / \mathrm{L}$ and sweet wines contain over $45 \mathrm{~g} / \mathrm{L}$. Higher sugar concentrations may apply to dry $(<9 \mathrm{~g} / \mathrm{L})$ or medium dry $(<18 \mathrm{~g} / \mathrm{L})$ when the level of total acidity (expressed in $\mathrm{g} / \mathrm{L}$ tartaric acid) is not less than $2 \mathrm{~g} / \mathrm{L}$ sugar or when the difference between the sugar and acid levels does not exceed $10 \mathrm{~g} / \mathrm{L}$, respectively (International Organisation of Vine and Wine, 2009). Data regarding wine information and chemical analyses were used as displayed in the website. Ethanol content was presented as percentage (v/v), titratable acidity (TA) as tartaric acid $(\mathrm{g} / \mathrm{L})$ and residual sugar $(\mathrm{RS})$ as $\mathrm{g} / \mathrm{L}$. All of these chemical parameters were reported by the winery that submitted the wine.

\subsection{Statistical analysis}

Data were analysed across three separate categories: chemical (TA, ethanol, RS), overall quality (complexity, harmonious and body) and sensory attributes, which included the sensory attributes described in Table 2. To compare the basic composition of the wines across sessions, analysis of variance was performed on the chemical parameters of alcohol, RS and TA, with mean separation by Tukey's HSD $(p<.05)$. Cluster analysis was performed on these wine expert sensory data using agglomerative hierarchical clustering (AHC) in XLSTAT (Addinsoft, Paris, France). Principal component analysis (PCA) was performed using the wine expert sensory data (XLSTAT). Correlations between wine chemistry

Table 1. Number of wine experts, wines and awards of the analysed editions of Mundus Vini Challenge.

\begin{tabular}{|c|c|c|c|c|c|c|}
\hline \multirow[b]{2}{*}{ Session } & \multirow[b]{2}{*}{ Number of wine experts } & \multirow[b]{2}{*}{ Number of wines } & \multicolumn{2}{|c|}{$\begin{array}{l}\text { Grand Gold } \\
\text { medals }\end{array}$} & \multicolumn{2}{|c|}{ Gold medals } \\
\hline & & & Red & White & Red & White \\
\hline Spring 2016 & 160 & 5000 & 21 & 2 & 561 & 199 \\
\hline Summer 2015 & 150 & 4300 & 11 & 4 & 431 & 156 \\
\hline Spring 2015 & 150 & - & 14 & 10 & 366 & 166 \\
\hline Summer 2014 & 164 & 4500 & 12 & 7 & 455 & 210 \\
\hline Spring 2014 & $-{ }^{a}$ & - & 5 & 5 & 321 & 115 \\
\hline
\end{tabular}

Notes: The wines included in this analysis were considered 'dry'. For more specific information, the reader is directed to www.mundusvini.com.

${ }^{\text {a }}$ Not reported. 
Table 2. Tasting scores presented to the judges in the challenge tasting sheet.

\begin{tabular}{|c|c|c|c|}
\hline & & Descriptors & $\begin{array}{l}\text { Possible assigned } \\
\text { scores }\end{array}$ \\
\hline \multirow{10}{*}{$\begin{array}{l}\text { Overall } \\
\text { evaluation }^{\mathrm{a}}\end{array}$} & \multirow[t]{2}{*}{ Visual } & Limpidity & 1,5 \\
\hline & & Aspect other than limpidity & $2,4,8,10$ \\
\hline & \multirow[t]{3}{*}{ Nose } & Genuineness & $2,3,4,5,6$ \\
\hline & & Positive Intensity & $2,4,6,7,8$ \\
\hline & & Quality & $8,10,12,14,16$ \\
\hline & \multirow[t]{4}{*}{ Taste } & Genuineness & $2,3,4,5,6$ \\
\hline & & Positive Intensity & $2,4,6,7,8$ \\
\hline & & Harmonious Persistence & $4,5,6,7,8$ \\
\hline & & Quality & $10,13,16,19,22$ \\
\hline & - & Overall Judgement & $7,8,9,10,11$ \\
\hline \multirow[t]{3}{*}{$\begin{array}{l}\text { Descriptor } \\
\text { evaluation }\end{array}$} & Nose (red) & $\begin{array}{l}\text { Vegetal, Eucalyptus, Red fruits, Confituré, Spicy, Empyreumatic, } \\
\text { Coffee/Chocolate, Oak, Animal, Other }\end{array}$ & $0,3,6,9$ \\
\hline & $\begin{array}{l}\text { Nose } \\
\text { (white) }\end{array}$ & $\begin{array}{l}\text { Vegetal, Mineral, Peach, Yellow Fruits, Exotic Fruits, Floral, Dried } \\
\text { fruits, Spicy, Honey, Oak, Butter }\end{array}$ & $0,3,6,9$ \\
\hline & Taste & Acidity, Sweetness, Bitterness, Astringency & $0,3,6,9$ \\
\hline $\begin{array}{l}\text { General } \\
\text { impression }\end{array}$ & - & Balance, Body, Complexity, Potential & $0,3,6,9$ \\
\hline \multirow[t]{2}{*}{ flaws } & Red & $\begin{array}{l}\text { Reduced, Corked, Earthy, Ethyl Acetate, Microbial, Brettanomyces, } \\
\text { Oxidation, Browning, Mousiness }\end{array}$ & Yes, No \\
\hline & White & $\begin{array}{l}\text { Reduced, Corked, Cooked, Ethyl Acetate, Microbial, Lactic, } \\
\text { Oxidation, Atypical Aging }\end{array}$ & Yes, No \\
\hline
\end{tabular}

${ }^{\mathrm{a}}$ The attributes are described in OIV (1994).

measurements and sensory attributes as evaluated by the wines experts were determined using correlation analysis (XLSTAT).

To examine the influence of each of sensory property on the likelihood of a wine receiving gold or grand gold medal, a logit ridge regression was used to fit a generalized linear model via penalized maximum likelihood (glmnet package, Friedman, Hastie, \& Tibshirani, 2010). Using deviance as the criterion, 10-fold cross validation was used to select the optimal penalty $(\lambda)$ as the minimum penalty at which the minimum mean cross-validated error was achieved. The probability cut-offs for predicting a sample as grand gold or gold awarded wine was determined using the Receiver Operating Characteristics (ROC) curves based on the comparison of sensitivity and specificity across a range of values for the ability to predict a dichotomous outcome.

Support vector machines (SVM) classification of grand gold and gold awarded wines was performed using 10-fold cross-validation for tuning the support vector machine parameters. The best parameters obtained were cost $=0.1$ and gamma $=0.5$. For both red and white wines, a radial basis function (RBF) was applied for the classification of samples into grand gold and gold awarded prizes to determine if the wines in these two categories were defined by different attributes. Prediction and classification were done on data collapsed across competition years. Computations were carried out in R (2018) using the R Studio interface (R Core Team, 2018).

\section{Results}

\subsection{Wine chemical analysis from 2014 to 2016}

The wine chemical parameters for red wines averaged for each challenge edition are shown in Table 3 for Grand Gold (GG) and Gold awarded wines. Only the wines with all 
Table 3. Chemical composition of red wines awarded Grand Gold (GG) and Gold (G) medals in the Mundus Vini Wine Challenge from the Spring of 2014 to the Spring of 2016 that were used in the data analysis.

\begin{tabular}{|c|c|c|c|c|c|c|}
\hline Parameters & Award & 2014 Spring & 2014 Summer & 2015 Spring & 2015 Summer & 2016 Spring \\
\hline \multirow[t]{2}{*}{ Ethanol (\% v/v) } & GG & $14.7 \pm 0.4^{\mathrm{a}}(5)^{\S}$ & $14.1 \pm 0.7^{b c}(10)$ & $14.5 \pm 0.6^{\mathrm{ab}}(13)$ & $14.0 \pm 0.6^{c}(7)$ & $14.1 \pm 0.8^{\mathrm{bc}}(12)$ \\
\hline & $\mathrm{G}$ & $14.1 \pm 0.7^{\mathrm{bc}}(259)$ & $14.2 \pm 0.8^{\mathrm{bc}}(407)$ & $14.1 \pm 0.7^{\mathrm{bc}}(286)$ & $14.1 \pm 0.7^{\mathrm{bc}}(356)$ & $14.1 \pm 0.6^{\mathrm{ab}}(339)$ \\
\hline \multirow[t]{2}{*}{ Residual Sugar (g/L) } & GG & $2.5 \pm 0.9^{\mathrm{a}}(5)$ & $3.4 \pm 3.3^{\mathrm{a}}(10)$ & $3.2 \pm 3.1^{\mathrm{a}}(13)$ & $1.9 \pm 1.5^{\mathrm{a}}(7)$ & $2.5 \pm 3.0^{\mathrm{a}}(12)$ \\
\hline & $\mathrm{G}$ & $2.8 \pm 2.0^{\mathrm{a}}(259)$ & $2.5 \pm 1.9^{\mathrm{a}}(407)$ & $2.7 \pm 2.1^{\mathrm{a}}(286)$ & $3.1 \pm 2.9^{\mathrm{a}}(356)$ & $2.5 \pm 1.9^{\mathrm{a}}(339)$ \\
\hline \multirow[t]{2}{*}{ Total acidity $(\mathrm{g} / \mathrm{L})^{*}$} & GG & $5.7 \pm 0.7^{\mathrm{a}}(5)$ & $5.2 \pm 1.0^{a}(10)$ & $5.4 \pm 0.7^{a}(13)$ & $5.7 \pm 0.6^{\mathrm{a}}(7)$ & $5.1 \pm 0.9^{a}(12)$ \\
\hline & G & $5.3 \pm 1.2^{\mathrm{a}}(259)$ & $5.3 \pm 1.1^{\mathrm{a}}(407)$ & $5.2 \pm 0.9^{a}(286)$ & $5.5 \pm 3.5^{a}(356)$ & $5.1 \pm 0.9^{a}(339)$ \\
\hline
\end{tabular}

Note: Different letters within a chemical parameter represent significant differences $(p<.05)$.

${ }^{\S}$ Mean \pm standard deviation (number of wines).

*Expressed as tartaric acid. 
reported chemical parameters were included in this evaluation. Within the wines awarded GG medals, significant differences in ethanol concentration across challenge editions were noted. Wines from the Spring 2014 and Spring 2015 were significantly higher in ethanol concentration compared to wines submitted in the Summer 2015 edition $(p<.05)$.

Significant differences were observed in the chemical parameters for wines awarded grand gold medals compared to those that received gold medals. Specifically, residual sugar levels were significantly different between the two groups, with the grand gold wines having significantly higher residual sugar levels $(2.85 \mathrm{~g} / \mathrm{L})$ compared to those awarded gold $(2.72 \mathrm{~g} / \mathrm{L})$ wines $(p=.016)$. Ethanol concentration also significantly varied with the medal awarded, with the grand gold wines having a significantly higher ethanol concentration (14.35\%) than the Gold wines $(14.11 \% \mathrm{v} / \mathrm{v})(p=.019)$. In red wines, across both medals, the average alcohol level was found to be relatively high $(14.1-14.7 \% \mathrm{v} / \mathrm{v})$ and total acidity was within the range of $4.8-5.7 \mathrm{~g} / \mathrm{L}$, close to the usual lower concentrations of $5 \mathrm{~g} / \mathrm{L}$ mentioned by Zoecklein, Fugelsang, Gump, and Nury (1999). The highest relative variability within chemical parameters was observed in the residual sugar concentrations. Figure 1 shows the residual sugar concentrations of all wines submitted to the competition editions, which are consistent with the concentrations reported by Loureiro et al. (2016) regarding previous challenge editions.

The composition of the white wines is shown in Table 4. Significant differences in the chemical parameters of total acidity $(p=.010)$ and ethanol $(p=.047)$ were observed between the gold and grand gold awarded wines. The grand gold wines were higher in ethanol $(13.65 \% \mathrm{v} / \mathrm{v})$ and lower in acidity $(5.21 \mathrm{~g} / \mathrm{L})$ compared to the gold medal wines, which had mean values of $13.21 \% \mathrm{v} / \mathrm{v}$ and $5.9 \mathrm{~g} / \mathrm{L}$, respectively. No differences across challenge editions were noted for any chemical parameters $(p>.05)$.

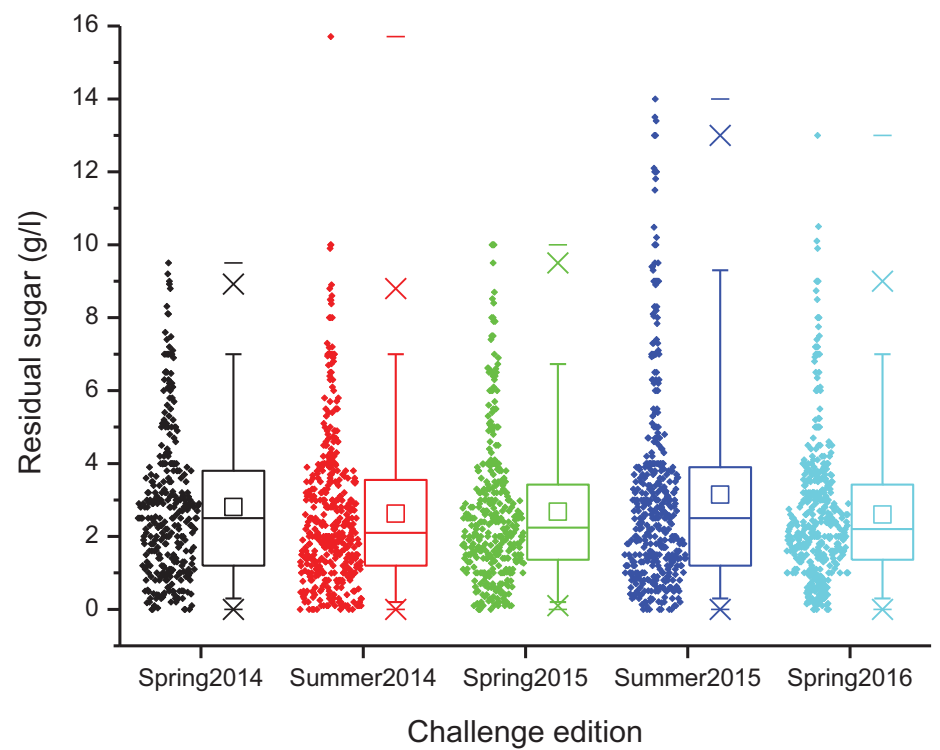

Figure 1. Box plot of the residual sugar concentrations $(\mathrm{g} / \mathrm{L}$ ) in all the red wines awarded a Gold medal in the Mundus Vini Wine Challenge from Spring 2014 to the Summer 2016 editions. 
Table 4. Chemical composition of white wines awarded Grand Gold (GG) and Gold (G) medals in the Mundus Vini Wine Challenge from 2014 to the Spring of 2016 that were used in the data analysis.

\begin{tabular}{|c|c|c|c|c|c|c|}
\hline Parameters & Awards & 2014 Spring & 2014 Summer & 2015 Spring & 2015 Summer & 2016 Spring \\
\hline \multirow[t]{2}{*}{ Ethanol (\%v/v) } & GG & $13.6 \pm 0.6^{\mathrm{a} \S}(4)$ & $13.8 \pm 0.4^{\mathrm{a}}(2)$ & $13.6 \pm 0.3^{\mathrm{a}}(4)$ & $13.5^{\mathrm{a}}(1)$ & $13.8 \pm 0.4^{\mathrm{a}}(2)$ \\
\hline & $\mathrm{G}$ & $13.4 \pm 0.7^{\mathrm{a}}(46)$ & $13.0 \pm 0.7^{\mathrm{a}}(106)$ & $13.2 \pm 0.7^{\mathrm{a}}(84)$ & $13.2 \pm 0.6^{\mathrm{a}}(74)$ & $13.2 \pm 0.6^{\mathrm{a}}(65)$ \\
\hline \multirow[t]{2}{*}{ Residual Sugar (g/L) } & GG & $3.4 \pm 2.7^{\mathrm{a}}(4)$ & $2.9 \pm 0.07^{\mathrm{a}}(2)$ & $2.0 \pm 0.7^{\mathrm{a}}(4)$ & $2.0^{\mathrm{a}}(1)$ & $2.6 \pm 0.1^{\mathrm{a}}(2)$ \\
\hline & $\mathrm{G}$ & $3.6 \pm 2.2^{\mathrm{a}}(46)$ & $4.1 \pm 2.3^{\mathrm{a}}(106)$ & $3.9 \pm 2.3^{\mathrm{a}}(84)$ & $4.9 \pm 3.1^{\mathrm{a}}(74)$ & $4.1 \pm 2.5^{\mathrm{a}}(65)$ \\
\hline \multirow[t]{2}{*}{ Total acidity $(\mathrm{g} / \mathrm{L})^{*}$} & GG & $5.3 \pm 1.2^{\mathrm{a}}(4)$ & $6.1 \pm 0.8^{\mathrm{a}}(2)$ & $4.8 \pm 1.2^{\mathrm{a}}(4)$ & $5.0^{\mathrm{a}}(1)$ & $4.9 \pm 0.6^{\mathrm{a}}(2)$ \\
\hline & G & $5.8 \pm 0.9^{\mathrm{a}}(46)$ & $6.2 \pm 1.2^{\mathrm{a}}(106)$ & $6.1 \pm 1.1^{\mathrm{a}}(84)$ & $6.2 \pm 1.0^{\mathrm{a}}(74)$ & $5.7 \pm 1.1^{\mathrm{a}}(197)$ \\
\hline
\end{tabular}

Note: Within a chemical parameter, different letters within an award represent significant differences $(p<.05)$.

${ }^{\S}$ Mean \pm standard deviation (number of wines).

*Expressed as tartaric acid. 
Table 5. Correlations between the white wine sensory and analytical measures.

\begin{tabular}{lccc}
\hline Variables & Ethanol $(\% \mathrm{v} / \mathrm{v})$ & Residual sugar $(\mathrm{g} / \mathrm{L})$ & Total acidity $(\mathrm{g} / \mathrm{L})$ \\
\hline Chemical parameters & & & \\
$\quad$ Ethanol & $\mathbf{1}$ & $\mathbf{0 . 7 6 6}$ & $\mathbf{- 0 . 7 2 6}$ \\
Residual sugar & $\mathbf{- 0 . 7 6 6}$ & $\mathbf{1}$ & $\mathbf{0 . 8 3 2}$ \\
$\quad$ Total acidity & $\mathbf{0 . 7 2 6}$ & $\mathbf{0 . 8 3 2}$ & $\mathbf{1}$ \\
Flavour attributes & & 0.487 & $\mathbf{0 . 6 6 4}$ \\
Acidity & $-\mathbf{0 . 6 4 6}$ & -0.378 & -0.129 \\
Sweetness & 0.553 & 0.246 & 0.407 \\
Bitterness & $-\mathbf{0 . 6 7 0}$ & -0.062 & -0.018 \\
Astringency & -0.067 & 0.452 & 0.567 \\
Yellow Friuts & -0.209 & -0.495 & -0.272 \\
Exotic Fruits & $\mathbf{0 . 6 5 8}$ & -0.239 & 0.163 \\
Floral & 0.331 & -0.323 & -0.496 \\
Dried Fruits & $\mathbf{0 . 6 7 8}$ & -0.258 & -0.280 \\
Spicy & 0.626 & -0.318 & -0.296 \\
Honey & 0.455 & 0.028 & 0.153 \\
Oak & -0.428 & 0.103 & 0.347 \\
Buttery & -0.404 & -0.110 & -0.243 \\
Green Vegetative & -0.343 & 0.414 & $\mathbf{0 . 6 5 9}$ \\
Mineral & -0.082 & 0.107 & 0.473 \\
Citrus & -0.245 & & \\
Overall quality & & 0.133 & 0.478 \\
Harmonious & 0.048 & 0.035 & 0.396 \\
Complex & 0.228 & 0.118 & 0.539 \\
Potential & 0.053 & -0.167 & 0.183 \\
Body & 0.384 & & \\
\hline
\end{tabular}

Note: Values in bold represent significance at $p<.05$.

While the average of residual sugar values meet the range of dry wines according to OIV $(<4 \mathrm{~g} / \mathrm{L}$, depending on total acidity level), many of these wines should be regarded as medium dry (4-12 g/L) or even semi-sweet (12-45 g/L) and be rated within different categories as advised by the OIV rules (OIV, 1994). The higher residual sugar content may have influenced the scores, masking wines that otherwise would seem bitter and astringent (Sáenz-Navajas, Fernández-Zurbano, \& Ferreira, 2012).

\subsection{Correlations between wine sensory and wine chemical measurements}

The results of wine and sensory analysis for all gold and grand gold awarded wines were analysed to observe possible correlations. In white wines (Table 5), one strong positive correlation was found between the chemical concentration of total acidity and residual sugar (0.832) which may be explained by the wine making decision to sweeten wines with an excessive sourness that are not necessarily perceived as sweet. This result is consistent with the low negative correlation between the residual sugar and perceived sweetness $(-0.378)$ and in line with the results presented by Blackman, Saliba, and Schmidtke (2010). Ethanol was negatively correlated with total acidity $(-0.726)$, which may be explained by longer grape ripening, in turn leading to higher ethanol and less acidity (Zoecklein et al., 1999). Consequently, ethanol also had a negative correlation to residual sugar ( -0.766$)$ likely due to the sweetening effect of high ethanol which makes additional sugar addition unnecessary. The flavour attributes and overall quality parameters were not strongly related with chemical analysis, yielding coefficients lower than 0.700 .

The correlation results for red wines also revealed interesting observations, different from those of white wines (Table 6). First, chemical parameters were not related among 
Table 6. Correlations between the red wine sensory and analytical measures.

\begin{tabular}{|c|c|c|c|}
\hline Variables & Ethanol (\%v/v) & Residual sugar (g/L) & Total acidity $(\mathrm{g} / \mathrm{L})$ \\
\hline \multicolumn{4}{|l|}{ Chemical parameters } \\
\hline Ethanol & 1 & -0.094 & 0.477 \\
\hline Residual sugar & -0.094 & 1 & -0.047 \\
\hline Total acidity & 0.477 & -0.047 & 1 \\
\hline \multicolumn{4}{|l|}{ Flavour attributes } \\
\hline Acidity & 0.040 & 0.017 & -0.089 \\
\hline Sweetness & 0.589 & 0.091 & 0.569 \\
\hline Bitterness & 0.038 & 0.634 & -0.437 \\
\hline Astringency & 0.525 & 0.457 & -0.112 \\
\hline Cherry & 0.545 & 0.034 & 0.398 \\
\hline Jammy & 0.504 & -0.039 & 0.726 \\
\hline Dried Fruits & 0.212 & 0.217 & 0.545 \\
\hline Spicy & 0.685 & 0.253 & 0.520 \\
\hline Smoky & 0.770 & 0.141 & 0.306 \\
\hline Coffee Chocolate & 0.821 & 0.009 & 0.529 \\
\hline Oak & 0.945 & -0.089 & 0.400 \\
\hline Barnyard & 0.198 & -0.029 & 0.261 \\
\hline Green Vegetative & -0.384 & 0.370 & -0.272 \\
\hline Minty Eucaliptus & 0.430 & 0.100 & 0.482 \\
\hline Red berries & 0.460 & -0.131 & 0.389 \\
\hline \multicolumn{4}{|l|}{ Overall quality } \\
\hline Harmonious & 0.776 & -0.235 & 0.461 \\
\hline Complex & 0.648 & -0.022 & 0.212 \\
\hline Potential & 0.753 & -0.163 & 0.252 \\
\hline Body & 0.725 & -0.156 & 0.238 \\
\hline
\end{tabular}

Note: Values in bold represent significance at $p<.05$.

them and, second, several correlations were found among flavour attributes and overall quality attributes. In particular, ethanol was positively correlated with smoky (0.770), coffee/chocolate (0.821) and oak (0.945), all consistent with oak aging (Oberholster et al., 2015). Three overall quality attributes (harmonious, potential, body) were strongly and positively correlated with ethanol, suggesting that assessors valued wine styles dominated by oak and ethanol. It is arguable that ethanol and noticeable oak elicit harmony and complexity, but that was the perception of the tasting panel. Residual sugar was not correlated with perceived sweetness, consistent with the masking effect of sugar on bitterness and astringency (Sáenz-Navajas et al., 2012). Accordingly, the four overall quality parameters were not correlated with sugar concentration.

\subsection{PCA and cluster analysis of gold and grand gold medal wines}

The sensory and overall quality attribute scores for each challenge edition and award for white wines were visualized using PCA (Figure 2). PC1 was primarily described by the complexity, body, potential and harmonious attributes of the wine while PC2 described the relationship between honey/dried fruit with green/vegetative notes. The PCA analysis separated the grand gold from the gold medal wines. The grand gold wines were separated across three quadrants. The grand gold wines of Summer 2015 and Spring 2014 had higher scores on the overall quality attributes while those of Spring 2015 and 2016 showed descriptors of exotic fruits and dried fruits. The grand gold wines of Summer 2014 were closer to the gold awarded wines. Gold awarded wines were placed in the lower left quadrant, corresponding to higher bitterness and green vegetative scores. 


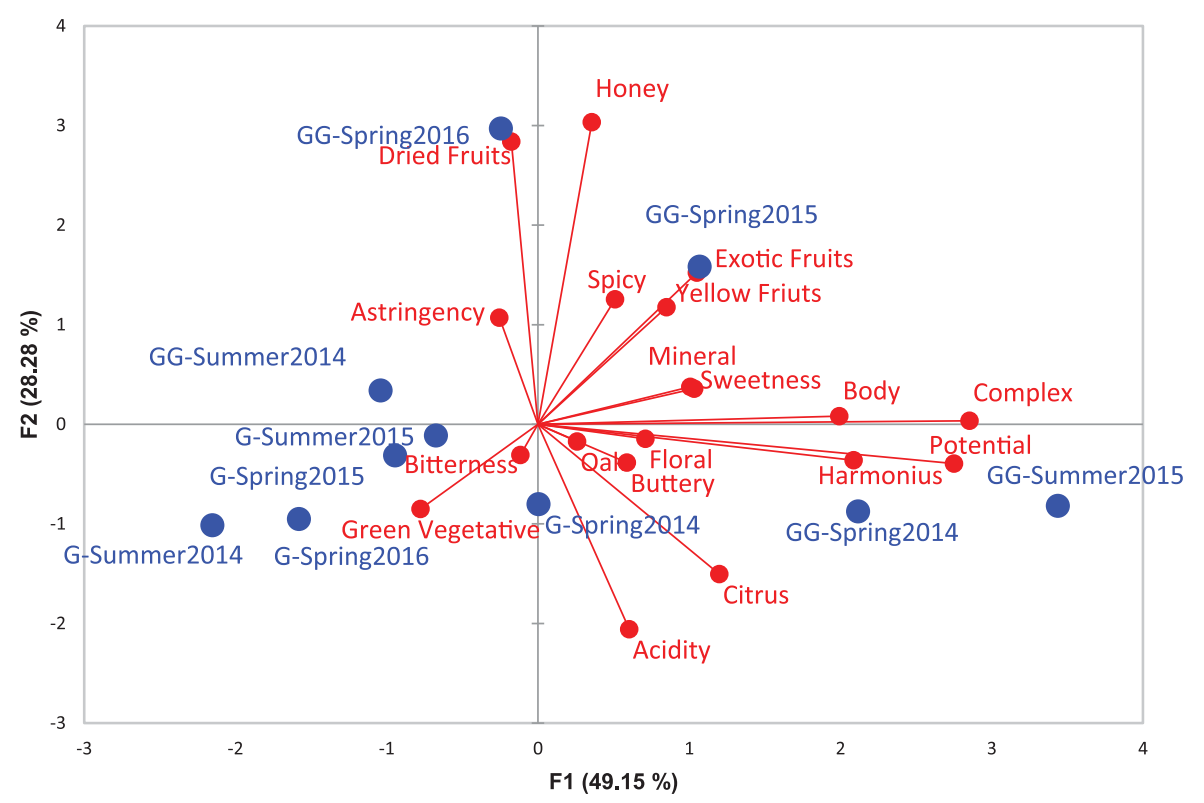

Figure 2. PCA of Gold (G) and Grand Gold (GG) awarded white wines and the relationship with sensory properties.

Further cluster analysis of the wines as profiled by the wine experts revealed three clusters (Figure 3). Cluster 1 contained grand gold awarded wines from two editions (Spring 2014 and Summer 2015), representing the wines with more potential, harmonious,

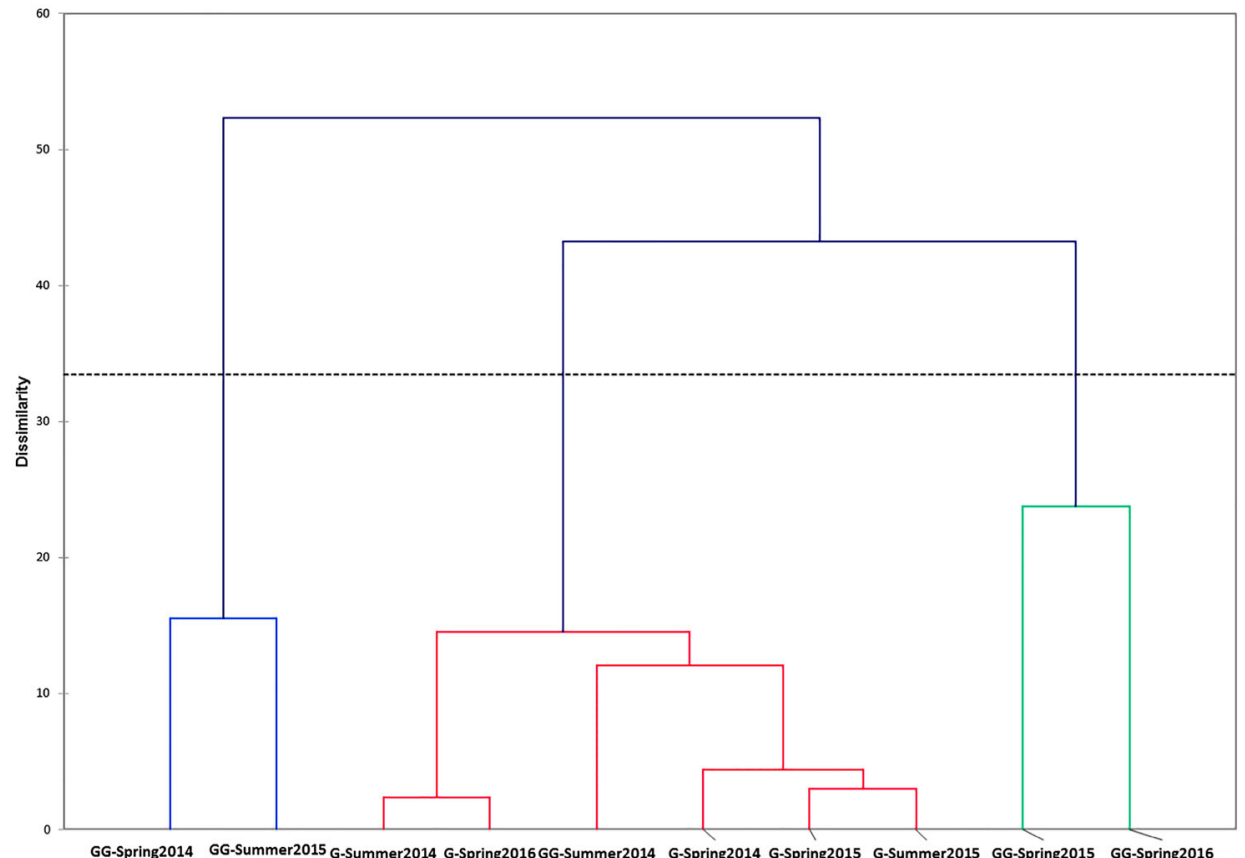

Figure 3. Cluster analysis of Gold and Grand Gold awarded white wines. 
complexity and body. Cluster 2 contained 5 gold awarded wines from all five editions and the grand gold awarded wines from Summer 2014, characterized by higher bitterness, green/vegetative characters. Finally, Cluster 3 had grand golds from two editions (Spring 2015 and Spring 2016) dominated by dried fruits, honey and exotic fruits. These results demonstrate that the grand gold wines from the Summer 2014 edition were most similar to gold awarded wines from all editions.

The results for red wines are shown in Figure 4. Grand gold wines loaded on the right side of the plot and were characterized by higher overall quality attributes, oak-related flavours (smoky, coffee/chocolate, spicy), astringency and sweetness. The gold wines were separated from the grand gold wines due to their high green/vegetative, bitterness and barnyard scores that placed the gold awarded wines on the left side of the plot. With the exception of the gold wines from Spring 2014 edition and grand gold wines from Summer 2015, this plot demonstrates a contrast the gold and the grand gold wines.

In the Cluster Analysis, Cluster 1 contained only the grand gold wines from two editions (Spring 2014 and Spring 2015), which were dominated by oak attributes and high overall quality scores (Figure 5). Cluster 2 contained grand gold wines from Spring 2014 and grand gold wine from both 2014 editions, as well as the Summer 2015 and Spring 2016 editions which were characterized by intermediate features between Cluster 1 and 3. Cluster 3 contained only gold medals wines from Summer 2014, the two editions of 2015 and Summer 2016 edition which were characterized by higher scores in green/vegetative, bitterness and barnyard.

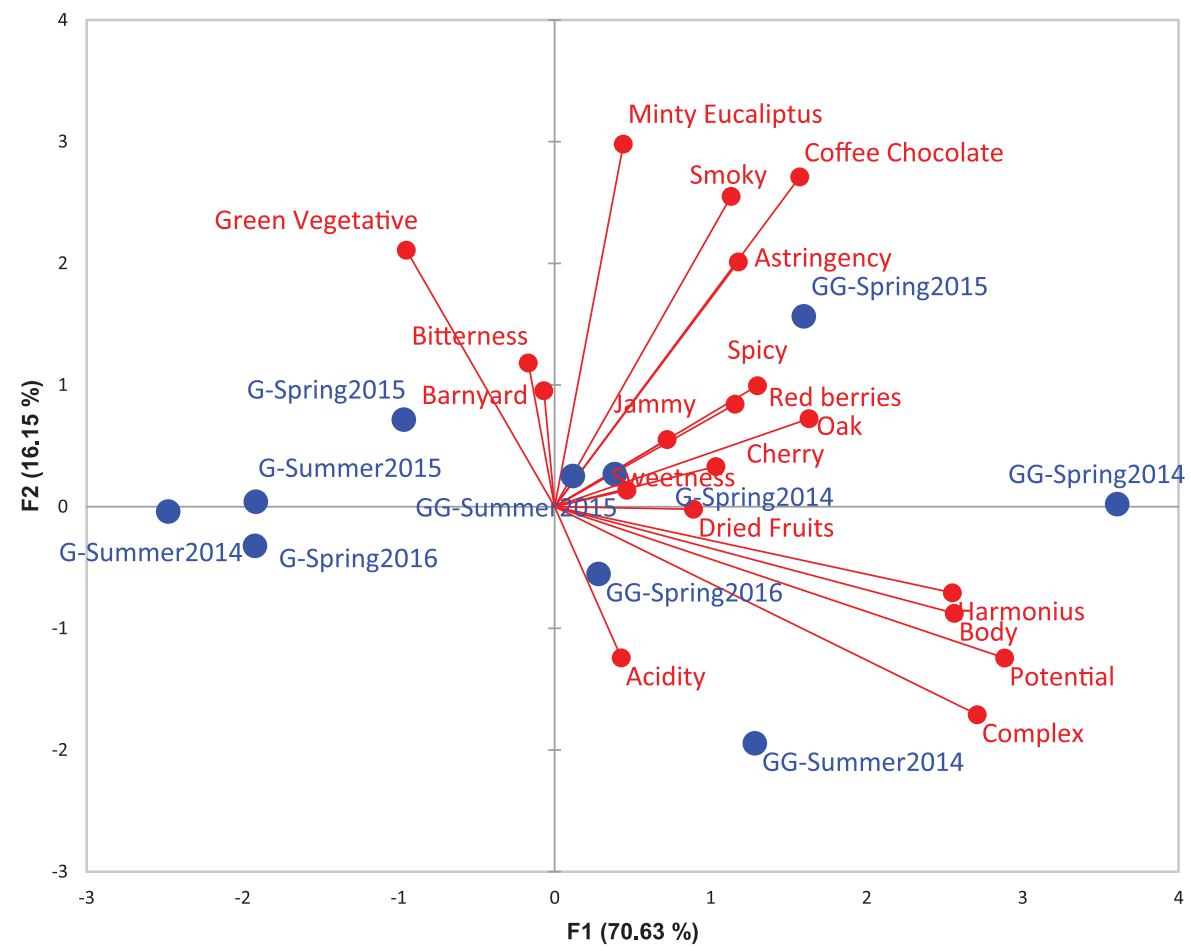

Figure 4. PCA of Gold (G) and Grand Gold (GG) awarded red wines and the relationship with sensory properties. 


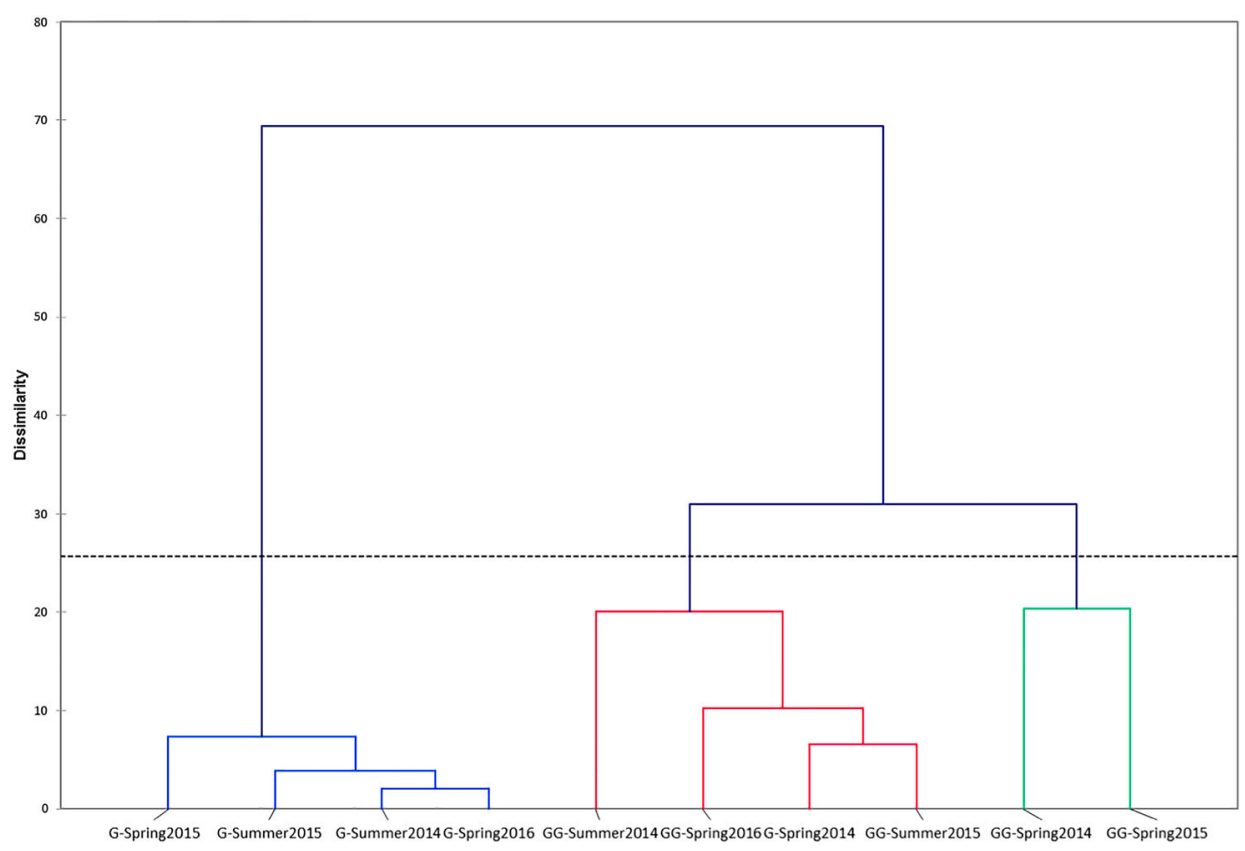

Figure 5. Cluster analysis of Gold and Grand Gold awarded red wines based on sensory evaluations.

Overall, in both red and white wines, there was a separation between gold and grand gold wines with only one cluster having both grand gold and gold medal wines. The gold awarded wines appeared to cluster together consistently while the grand gold medal awarded wines fell into two different clusters for both whites and reds. The separation between both awards was mainly due to bitterness and green/vegetative descriptors in both wine colours with higher scores in the gold medal awarded wines. In addition, the red wines awarded gold medals were also characterized by having higher barnyard scores, which are not relevant in white wines.

\subsection{Wine medal prediction and classification}

Logistic ridge regression was used to determine the predictors of wine medal for red and white wines. Results showed seven significant predictors of red wine medal while three predictors were obtained for white wine medal awards (Table 7). Overall prediction accuracy of $92 \%$ was obtained in both red and white wines cases even though most of this was due to the correct prediction of gold medals, likely as a result of a large number of gold medals in the dataset.

Specific attributes were identified as predictors. The single positive sensory predictor for white wines awarded grand gold medals was exotic fruits, while overall quality indicators were body and complexity. Negative predictors were acidity and astringency. Red wines had a higher number of predictors than white wines. For red wines, positive flavour predictors of medals were dried fruits and spicy while negative predictors were green vegetative and red berries. The overall quality predictors were body, complexity and potential. Interestingly, both red and white wines showed the highest $\beta$-value for 
Table 7. Log odd ratios of significant predictors of white and red wine award Grand Gold medal.

\begin{tabular}{llr}
\hline Wine type & \multicolumn{1}{c}{ Predictor } & $\beta$-value \\
\hline White & Exotic fruit & 0.24 \\
& Body & 0.12 \\
& Complex & 1.17 \\
& Acidity & -0.16 \\
Red & Astringency & -0.04 \\
& Dried fruit & 0.09 \\
& Spicy & 0.11 \\
& Green vegetative & -0.39 \\
& Red berries & -0.17 \\
& Body & 0.10 \\
& Complex & 0.71 \\
& Potential & 0.35 \\
\hline
\end{tabular}

complexity, suggesting that for both wines, this was the strongest predictor of a grand gold medal award.

Using support vector machines for the classification of wines into Grand Gold and Gold, results showed a high classification accuracy of $97 \%$. This indicates that wines awarded Grand Gold and Gold were defined by different scores in the attributes used by the judges. This high classification accuracy also indicates that non-linear methods could be very useful to better model the relationships between the wine attributes and the award outcome.

\section{Discussion}

The results presented in this work reflect the chemical and sensory features of the wines awarded the highest scores in a large international challenge. Despite the high number of wines and the absence of jury calibration, several common characteristics were found among these wines using different statistical tools. Regarding chemical parameters, high ethanol levels and a high range of sugar concentrations, mainly in red wines, were observed. These high ethanol levels were observed in red wines with oak-related flavours i while residual sugar was not perceived as eliciting sweetness. These results align with the conclusions drawn by Hopfer and Heymann (2014) reporting that red wine gold and double gold medals showed detectable aromas of fruit and oak and absent or marginal notes of vegetal-green, low astringency and bitterness, and higher sweetness. Broad consumer preferences for these wine features, consistent with the socalled international commercial style, have also been described in other countries and cultures, as reviewed by Francis and Williamson (2015).

The overall quality parameters of harmonious, complex, potential and body are in the accordance with the dimensions of wine quality recognized by individuals highly involved with wine, as described by Charters and Pettigrew (2007). These authors also stated that individuals with low wine involvement associated smoothness with quality, contrary to those individuals with high wine involvement. An individual with the medium-involvement level was defined as one having an intermediate preference but resembling more low-involved when considering taste and appearance.

Likely, the results of the Mundus Vini Challenge reflect the preferences of what we may consider a medium-involvement level, although jurors were recruited among wine professionals. In fact, the positive correlation between ethanol and the overall quality parameters casts some doubt on their ability as a panel to recognize these quality 
parameters as high ethanol reduces wine harmony and complexity. It is also possible that the tasting sequence, specifically mixing high and low ethanol wines, results in favouring the former wines as demonstrated by King, Dunn, and Heymann (2013). Liking of high residual sugar levels is also more characteristic of novices (Blackman et al., 2010; SenaEsteves, Mota, \& Malfeito-Ferreira, 2018). Sweetness remains one of the most important attributes driving consumer liking scores while bitterness and sourness are associated with disliking (Rodrigues \& Parr, 2018). In addition, sugar levels also increase the sensation of wine body (Sáenz-Navajas et al., 2012) and so probably assessors were rating better an overall quality attribute that is easily manipulated at the winery level.

However, it is also possible to explain these results by the OIV tasting method as suggested by Loureiro et al. (2016). These authors speculated that the high number of wines in the tasting sequence, the short tasting time and the weight of the intensity scores of smell and taste to the overall evaluation contribute to valorize wines consistent with the international commercial style. In large tasting challenges, cool-climate wine styles, particularly sour white wines and red wines with some bitterness and astringency, are less recognized unless the judges are familiar with this style. The authors attributed this finding to the different preferences of the judges, which is influenced by the background and culture of the judge, as well as level of expertise.

The main limitation of this work was related with retrieving the data form the website. Chemical analysis was used as provided by the wine producer and could not be checked. In addition, tasters were not trained together to harmonize the attribute descriptors and quality indicators. However, globally the outputs are consistent with empirical knowledge shared by wine professionals and highlight the stylistic bias induced by the OIV tasting methodology.

\section{Conclusion}

The results from this work showed that large wine challenges tend to favour wine styles consistent with the so-called international style with high ethanol and sugar higher than the level considered for dry wines $(4 \mathrm{~g} / \mathrm{L})$. Flavours that may be associated with sweetness, including exotic fruits in white wines and dried fruit and spicy in reds, increased the odds only of being awarded a grand gold or gold medal, as opposed to the perception of acidity and astringency in whites and of green/vegetative and red berries in reds. These results suggest that wine modulation, either in the vineyard to obtain overripe grapes, or in the winery to smooth mouthfeel by sugar addition, are effective measures to increase the chance of a wine to be awarded a gold medal.

\section{Acknowledgements}

The authors are indebted to the ISA Viticulture and Enology master students Susana Almeida, Beatriz Fernandes, Enrico Pignone and Francesco Ceciliani for retrieving the data from the Mundus Vini website.

\section{Disclosure statement}

No potential conflict of interest was reported by the authors. 


\section{Funding}

This work was partially supported by national funds from Fundação para a Ciência e a Tecnologia (FCT) through the research unit UID/AGR/04129/2013 (LEAF).

\section{References}

Blackman, J., Saliba, A., \& Schmidtke, L. (2010). Sweetness acceptance of novices, experienced consumers and winemakers in Hunter Valley Semillon wines. Food Quality and Preference, 21(10), 679683.

Bodington, J., \& Malfeito-Ferreira, M. (2017). The 2016 wines of Portugal challenge: General implications of more than 8400 wine-score observations. Journal of Wine Research, 28, 313-325.

Charters, S., \& Pettigrew, S. (2007). The dimensions of wine quality. Food Quality and Preference, 18(7), 997-1007.

Cliff, M., \& King, M. (1997). The evaluation of judges at wine competitions: The application of Eggshell plots. Journal of Wine Research, 8, 75-80.

Cliff, M., \& King, M. (1999). Use of principal component analysis for the evaluation of judge performance at wine competitions. Journal of Wine Research, 10, 25-32.

Francis, I. L., \& Williamson, P. O. (2015). Application of consumer sensory science in wine research. Australian Journal of Grape and Wine Research, 21, 554-567.

Friedman, J., Hastie, T., \& Tibshirani, R. (2010). Regularization paths for generalized linear models via coordinate descent. Journal of Statistical Software, 33(1), 1-22.

Herbst, F., \& Von Arnim, C. (2009). The role and influence of wine awards as perceived by the South African wine consumers. Acta Commercii, 9, 90-101.

Hodgson, R. T. (2008). An examination of judge reliability at a major U.S. Wine competition. Journal of Wine Economics, 3(2), 105-113.

Honoré-Chedozeau, C., Ballester, J., Chatelet, B., \& Lempereur, V. (2015). Wine competition: From between-juries consistency to sensory perception of consumers. BIO Web of Conferences, 5, 03009-03015.

Hopfer, H., \& Heymann, H. (2014). Judging wine quality: Do we need experts, consumers or trained panelists? Food Quality and Preference, 32, 221-233.

International Organisation of Vine and Wine. (2009). OIV standard for international wine competitions and spirituous beverages of vitivinicultural origin (OIV-CONCOURS 332A-2009) and Guidelines for granting OIV patronage of international wine and spirituous beverages of vitivinicultural origin competitions (OIV-concours332b-2009). Paris.

King, E., Dunn, R., \& Heymann, H. (2013). The influence of alcohol on the sensory perception of red wines. Food Quality and Preference, 28, 235-243.

Loureiro, V., Brasil, R., \& Malfeito-Ferreira, M. (2016). A new wine tasting approach based on emotional responses to rapidly recognize classic European wine styles. Beverages, 2(1), 6.

Oberholster, A., Elmendorf, B., Lerno, L., King, E., Heymann, H., Brenneman, C., \& Boulton, R. (2015). Barrel maturation, oak alternatives and micro-oxygenation: Influence on red wine aging and quality. Food Chemistry, 173, 1250-1258.

O.I.V. (1994). Standard on international wine competitions. Paris: Office International de la Vigne et du Vin.

OIV. (2009). OIV standard for international wine competitions and spirituous beverages of vitivinicultural origin (OIV-CONCOURS 332A-2009) and Guidelines for granting OIV patronage of international wine and spirituous beverages of vitivinicultural origin competitions. Paris: International Organisation of Vine and Wine.

Peattie, S. (1995). Promotional competitions - a winning technique for wine marketing. International Journal of Wine Marketing, 7(3), 31-48.

R Core Team. (2018). $R$ : A language and environment for statistical computing. Vienna: R Foundation for Statistical Computing. Retrieved from https://www.R-project.org/

Rodrigues, H., \& Parr, W. (2018). Contribution of cross-cultural studies to understanding wine appreciation: A review. Food Research International. doi:10.1016/j.foodres.2018.09.008 
Sáenz-Navajas, M. P., Fernández-Zurbano, P., \& Ferreira, V. (2012). Contribution of nonvolatile composition to wine flavor. Food Reviews International, 28(4), 389-411.

Scaman, C., Dou, J., Cliff, M., Yuksel, D., \& King, M. (2001). Evaluation of wine competition judge performance using principal component similarity analysis. Journal of Sensory Studies, 16, 287-300.

Sena-Esteves, M., Mota, M., \& Malfeito-Ferreira, M. (2018). Patterns of sweetness preference in red wine according to consumer characterization. Food Research International, 106, 38-44.

Zoecklein, B., Fugelsang, K., Gump, B., \& Nury, F. (1999). Wine analysis and production. In Hydrogen ion $(p H)$ and fixed acids (Ch. 4) (pp. 76-88). New York, NY: Kluwer Academic/Plenum. 
Copyright of Journal of Wine Research is the property of Routledge and its content may not be copied or emailed to multiple sites or posted to a listserv without the copyright holder's express written permission. However, users may print, download, or email articles for individual use. 